\title{
Tropospheric forcing of the boreal polar vortex splitting in January 2003
}

\author{
D. H. W. Peters ${ }^{1}$, P. Vargin ${ }^{2}$, A. Gabriel ${ }^{1}$, N. Tsvetkova ${ }^{2}$, and V. Yushkov ${ }^{2}$ \\ ${ }^{1}$ Leibniz Institute for Atmospheric Physics at the University of Rostock, Kühlungsborn, Mecklenburg, Germany \\ ${ }^{2}$ Central Aerological Observatory, Dolgoprudny, Moscow region, Russia
}

Received: 24 May 2010 - Revised: 26 September 2010 - Accepted: 10 November 2010 - Published: 26 November 2010

\begin{abstract}
The dynamical evolution of the relatively warm stratospheric winter season 2002-2003 in the Northern Hemisphere was studied and compared with the cold winter 2004-2005 based on NCEP-Reanalyses. Record low temperatures were observed in the lower and middle stratosphere over the Arctic region only at the beginning of the 2002-2003 winter. Six sudden stratospheric warming events, including the major warming event with a splitting of the polar vortex in mid-January 2003, have been identified. This led to a very high vacillation of the zonal mean circulation and a weakening of the stratospheric polar vortex over the whole winter season. An estimate of the mean chemical ozone destruction inside the polar vortex showed a total ozone loss of about 45 DU in winter 2002-2003; that is about 2.5 times smaller than in winter 2004-2005.

Embedded in a winter with high wave activity, we found two subtropical Rossby wave trains in the troposphere before the major sudden stratospheric warming event in January 2003. These Rossby waves propagated north-eastwards and maintained two upper tropospheric anticyclones. At the same time, the amplification of an upward propagating planetary wave 2 in the upper troposphere and lower stratosphere was observed, which could be caused primarily by those two wave trains. Furthermore, two extratropical Rossby wave trains over the North Pacific Ocean and North America were identified a couple of days later, which contribute mainly to the vertical planetary wave activity flux just before and during the major warming event. It is shown that these different tropospheric forcing processes caused the major warming event and contributed to the splitting of the polar vortex.
\end{abstract}

Keywords. Meteorology and atmospheric dynamics (Middle atmosphere dynamics)

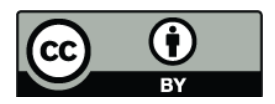

Correspondence to: D. H. W. Peters (peters@iap-kborn.de)

\section{Introduction}

Understanding the observed atmospheric circulation is important in order to improve the modeling of dynamical processes in the troposphere and stratosphere, for example in order to provide seasonal predictions of large-scale processes. The atmospheric phenomenon of a sudden stratospheric warming (SSW) event is a significant example of dynamical linkage between troposphere and stratosphere. A SSW event was first discovered by Scherhag (1952) over Berlin in winter 1951-1952 when he found a strong and sudden temperature increase in the stratosphere. Extended reviews of SSW observations and theory can be found in the papers of Schoeberl (1978) and McIntyre (1982). The splitting phenomenon during a SSW event was extensively described in the review of McIntyre (1982) because it is a remarkable dynamical event.

We know that a SSW event is a large-scale phenomenon with hemispheric impacts as reported in many textbooks (e.g., Andrews et al., 1987). In particular SSW events are a prominent feature of interannual variability of the extratropical stratosphere over the Arctic region with the strongest SSW event ever observed in January 2009 (Labitzke and Kunze, 2009; Manney et al., 2009). A SSW event could lead to a fast and significant increase of the polar stratospheric temperature (up to $40 \mathrm{~K}$ ) and to a reversal of mean zonal circulation. Moreover, the polar stratospheric vortex could be shifted off the pole, or in some cases a splitting event may occur (e.g., Schoeberl, 1978; McIntyre, 1982; Charlton and Polvani, 2007). These changes of extratropical stratosphere are not confined in the stratosphere, but they could penetrate upward into the mesosphere or downward to lower troposphere with a delay of about two months (e.g., Baldwin and Dunkerton, 2001). Changes of the polar vortex's strength influence phases of the NAO: a negative phase of the NAO correlates with a weaker polar vortex and a positive phase

Published by Copernicus Publications on behalf of the European Geosciences Union. 
with a stronger polar vortex (Castanheira and Graf, 2007). Additionally, the impact of SSW on the stratosphere and troposphere is not confined to middle and high latitudes. Using satellite data, Eguchi and Kodera (2007) found a relationship between the SSW event over the Arctic and the cooling of equatorial troposphere. This relationship occurs due to an enhanced meridional circulation.

Matsuno (1971) investigated the main physical process of SSW generation. He showed that a planetary wave packet transports easterly angular momentum from the troposphere into the stratosphere, whereby the divergence of the EliassenPalm (E-P) flux of the waves decelerates the zonal mean zonal wind inducing a sudden warming in the extratropical stratosphere. This fundamental theory has been extended in many papers, for instance by including instability processes of a forced wave (Plumb, 1981) or by considering a forced triad of resonant waves (Peters, 1985). Furthermore, Esler et al. (2006) studied the instability of a barotropic wave with constant tropospheric forcing as a possible process for the onset of the austral SSW event in September 2002. They found that an amplifying tropospheric forcing is not needed to set up the main characteristics for the development of the SSW event.

Other authors have emphasized the importance of additional tropospheric forcing processes in setting up SSW events as expected from the work of Matsuno (1971). For instance, Harada et al. (2010) showed the important role of subtropical or extratropical Rossby wave trains for the evolution of the boreal major warming event in January 2009. An example of a very early major SSW in December 1984 on the Northern Hemisphere was elaborately described by Randel and Boville (1987). For the first observed austral major SSW in September 2002 Niishi and Nakamura (2004), Scaife et al. (2005), and Peters et al. (2007) identified an additional tropospheric forcing in the pre-warming phase. Note also that Limpasuvan et al. (2004) showed in a composite study that the evolution of SSW events is well characterized by a life cycle process.

The lower stratospheric temperatures are strongly correlated with lower stratospheric ozone for both Arctic and Antarctic winter periods, with a coherent sensitivity of about $\Delta \mathrm{O}_{3} / \Delta T \approx 8-10 \mathrm{DU} \mathrm{K}^{-1}$ for dynamically induced ozonetemperature variations for the Northern Hemisphere (Randel and Cobb, 1994; Randel and Wu, 1999). It is also known from general circulation model studies (e.g., Graf et al., 1998) that the observed decrease of lower stratospheric ozone in the Northern Hemisphere during the 1980s and early 1990s contributed substantially to lower stratospheric cooling. Additionally, based on model studies with interactive chemistry, the wave-driven ozone and temperature changes during northern winter are substantially enhanced (on the order of $30 \%$ ) if ozone-temperature interaction via radiation is taken into account (Gabriel and Schmitz, 2003). Shindell et al. (1997) showed in a model study that the interannual variability of the Antarctic ozone hole strongly in- teracts with tropospheric wave variability, i.e. the variations in the polar vortex and in temperature-dependent polar ozone depletion, which are induced by tropospheric forcing mechanisms, may have a substantial feedback on the tropospheric and stratospheric wave propagation. Note here that Randel and $\mathrm{Wu}$ (1999) found an overall similarity in the coherent space-time structure of ozone loss and cooling patterns for the Arctic and Antarctic. These variations are driven by the different buildup of tropospheric wave energy. In the framework of our paper we discuss how these feedbacks may play a role in generating the different variations in the stratosphere during the 2002-2003 and 2004-2005 winters. For the inverse direction Mukougawa et al. (2009) showed that the long-time (up to 30 days) predictive skill of a tropospheric annular mode is lower in winter 2004-2005 than in winter 2003-2004 in which a major warming occurred in January.

Generally we have to recognize that each SSW event has its own typical characteristics, which should be studied in detail. From such investigations we improve our knowledge about the set up and evolution of SSW events including the possible splitting of the polar vortex. This knowledge could give also a contribution to the improvement of climate models, in which the seasonal behavior of large-scale processes differs from observations, especially from winter to spring (SPARC CCMVal, 2010). Furthermore, the prediction of SSW events over periods longer than 10-14 days is still an open problem.

We focus in this observational study on the sudden major warming event in January 2003 in order to identify generation processes and to study the role of tropospheric forcing processes and their role in the splitting process of the polar vortex in more detail. As an example for this remarkable splitting process of the polar vortex, the evolution of the geopotential height anomaly (deviation from zonal mean) at $30 \mathrm{hPa}$ is shown in Fig. 1. For the period of 16-22 January 2003 the development of both cyclonic centers is presented. The low over Siberia extended to Canada, split into two lows, and then over Canada intensified.

The paper is organized in the following manner. The data used and the methodology of applied diagnoses are described in Sect. 2. For comparison, diagnostic results of the dynamical evolution for two boreal winters 2002-2003 and 20042005 are provided and an estimate of the polar chemical ozone loss is given in Sect. 3. The study of tropospheric forcing processes of the major SSW and polar vortex splitting in January 2003 is presented in Sect. 4. The discussion and conclusion are given in Sect. 5.

\section{Data and method of analysis}

Daily global NCEP-Reanalysis data of geopotential, temperature, zonal and meridional wind at 17 pressure levels from 1000 to $10 \mathrm{hPa}(\sim 32 \mathrm{~km})$ with a horizontal resolution of $2.5^{\circ} \times 2.5^{\circ}$ were used to diagnose dynamical processes in 

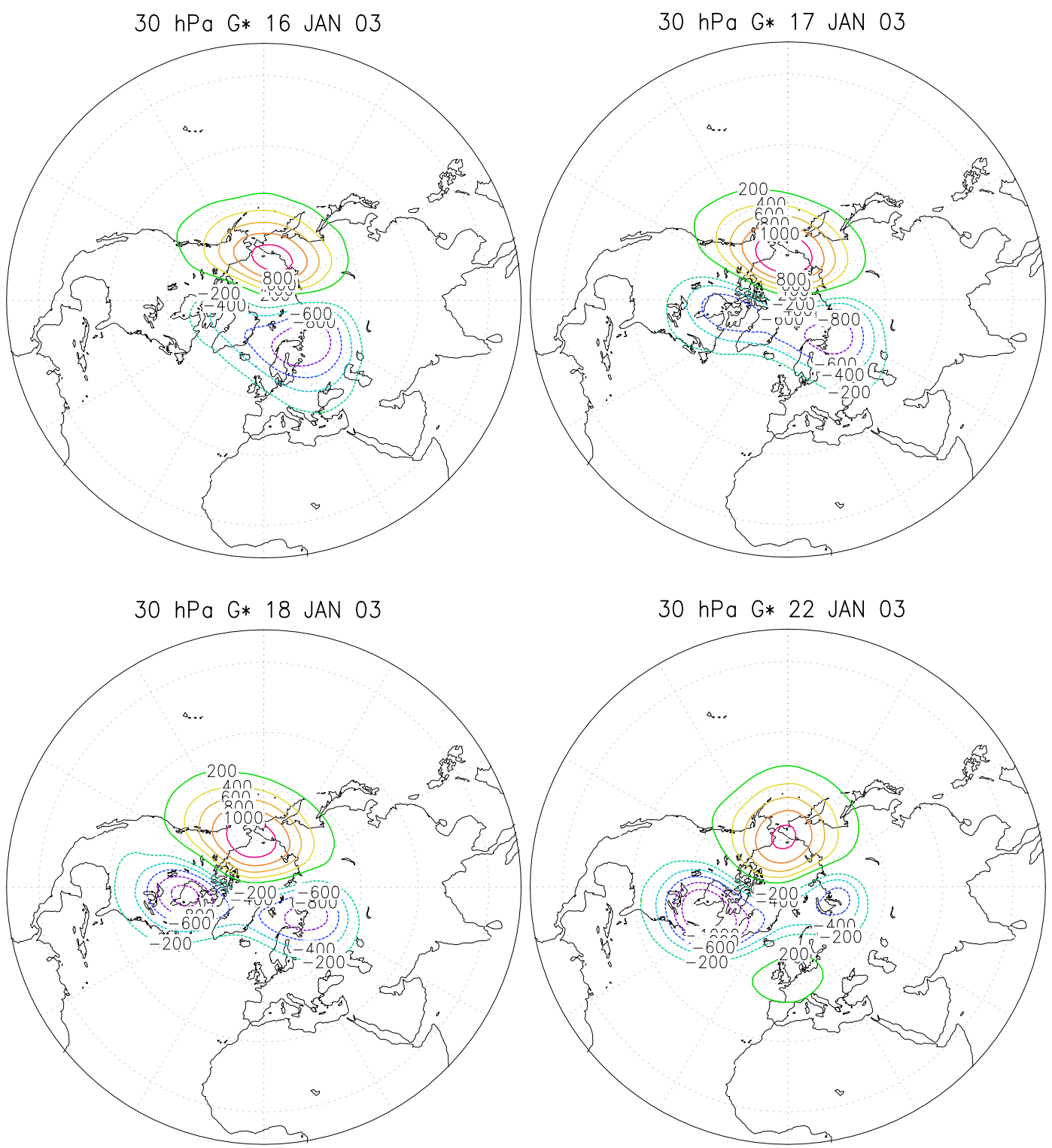

Fig. 1. Stereographic projection of geopotential height $G^{*}$ (dam) at $30 \mathrm{hPa}$ for $16,17,18$ and 22 January 2003 . $G^{*}$ perturbation is defined as deviation from zonal mean.

the troposphere and stratosphere. The evolution of quasistationary planetary waves with zonal wave number $k=$ $\{1,2,3\}$ has been analyzed using a Fourier decomposition.

The propagation of quasi-stationary waves into the boreal extratropics during winters 2002-2003 and 2004-2005 was studied by using the three-dimensional wave activity flux developed by Plumb (1985). It is known as an extended Eliassen-Palm (EP) flux or Plumb flux due to the fact that its zonal average is equal to the well-known EP flux. Under the assumption of slow variability of the basic state (socalled WKB limit), the Plumb flux vectors are proportional to the group velocity of a planetary wave packet indicating the direction of propagation of the wave activity. In addition,
Plumb flux vectors are useful to localize regions of wave activity sources and sinks. Moreover, the divergence of zonally averaged Plumb fluxes displays the influence of wave activity on the zonal mean circulation - its acceleration or deceleration.

The three-dimensional Plumb vector $\boldsymbol{F}$ was defined by Plumb (1985) as:

$$
\begin{aligned}
\boldsymbol{F} & =\left(F_{\lambda}, F_{\varphi}, F_{\mathrm{z}}\right) \\
& =\frac{p}{p_{\mathrm{s}}} \cos \varphi \cdot\left(\begin{array}{l}
v^{* 2}-\frac{1}{2 \Omega a \cdot \sin 2 \varphi} \frac{\partial\left(v^{*} \Phi^{*}\right)}{\partial \lambda} \\
-u^{*} v^{*}+\frac{1}{2 \Omega a \cdot \sin 2 \varphi} \frac{\left.\partial u^{*} \Phi^{*}\right)}{\partial \lambda} \\
\frac{2 \Omega \cdot \sin \varphi}{S}\left[v^{*} T^{*}-\frac{1}{2 \Omega a \cdot \sin 2 \varphi} \frac{\partial}{\partial \lambda}\left(T^{*} \Phi^{*}\right)\right]
\end{array}\right)
\end{aligned}
$$

Ann. Geophys., 28, 2133-2148, 2010 

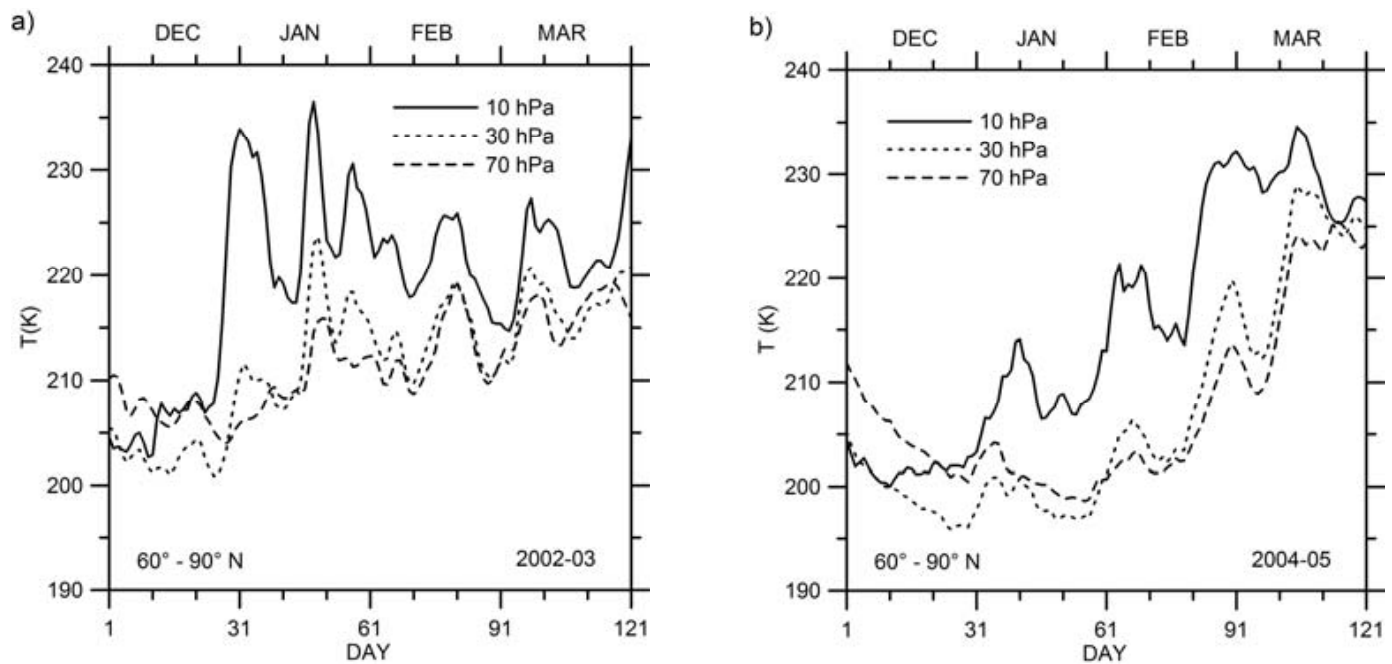

Fig. 2. Zonal mean temperature (K) averaged over $60^{\circ}-90^{\circ} \mathrm{N}$ at 70,30 and $10 \mathrm{hPa}$ from 1 December to $31 \mathrm{March}$ (a) winter $2002-2003$ and (b) winter 2004-2005.

where $F_{\lambda}, F_{\varphi}, F_{\mathrm{z}}$ are the longitudinal, latitudinal and vertical components of the Plumb flux vector, with $\lambda$ - longitude, $\varphi-$ latitude, $z$-altitude, $u, v$ are zonal and meridional velocity, $\Phi$ is geopotential, $T$ - temperature, $p$ - pressure, and $p_{\mathrm{s}}-$ pressure at Earth surface, $a$ stands for Earth's radius, $\Omega$ for Earth's angular velocity, with $S=\frac{\partial \bar{T}}{\partial z}+\frac{\kappa \bar{T}}{H}$ is static stability, $\kappa=R / c_{p} \approx 0.286$ and represents scale height; a star indicates the deviation from the zonal average and a bar the zonal mean.

Note that Plumb flux vector calculations have been applied for different time scales, e.g., from climatological studies of wave activity (e.g., Plumb, 1985) of 10 years down to composite studies of 5 days (e.g., Nishi and Nakamura, 2004; Peters et al., 2007). Here we are using data averages over 3-5 days in the calculation of the Plumb flux vectors.

A lag-correlation method is also applied for January 2003. The centre of the developing second low over Canada was used as a reference point $\left(90^{\circ} \mathrm{W}, 60^{\circ} \mathrm{N}\right.$ ) at $30 \mathrm{hPa}$ (see Fig. 1) in order to show the evolution of a coherent structure down to the troposphere for negative or positive lags from 1 to 4 days. This method was described extensively and applied to geopotential height anomalies by Fraedrich and Lutz (1987) and Randel (1988). In our case we use 6-hourly NCEPReanalysis values from 5-31 January 2003 with the 18th as the centre point. Thus we have an ensemble of 108 samples covering 27 days. Fraedrich and Lutz (1987) estimated a maximum of the mean decorrelation time-scale of about 4.1 days for 15 winters with unfiltered data. If we apply this decorrelation time-scale we have an effective number of independent samplings of about 6 . With Student's t-test one obtains the following $(80 \%, 90 \%, 95 \%)$ significant correlation coefficients: $(0.43,0.61,0.73)$. These significant lagcorrelation patterns indicate wave group vectors as shown by Fraedrich and Lutz (1987).
In order to examine Rossby wave trains in the middle and upper troposphere which could contribute to the maintenance of blocking anticyclones we used Hovmöller diagrams of squared meridional velocity as a function of longitude (e.g., Chang, 1993; Peters et al., 2007). Interpolated daily NOAAdata of outgoing long-wave radiation (OLR) are taken into account to reveal regions with deep convection and enhanced divergence.

In the present study the implication of the different stratospheric winter temperatures of the polar vortex is determined by estimating the chemical ozone loss. We employed a method based on the calculation of the vortex average rate of the ozone mixing ratio change at fixed potential temperature levels considering ozone inflow from higher levels by diabatic downward transport of air masses (Tsvetkova et al., 2007). Satellite data of SAGE III (McCormick et al., 1993) and in-situ balloon measurements of vertical ozone performed at Salekhard station in northern Russia $\left(66^{\circ} \mathrm{N}\right.$, $66^{\circ} \mathrm{E}$ ) were used to verify the chemical ozone loss rate during Arctic winter 2002-2003 and 2004-2005.

\section{Dynamical evolution for winters, 2002-2003 and 2004-2005}

The record low temperatures of the boreal polar stratosphere observed during the early wintertime period of 2002-2003 have never been detected during the last 57 years. The seasonal evolution of zonal mean temperature for the polar region is shown in Fig. 2a. After a cold start to the winter, a SSW occurred at the end of December 2002. This SSW generated a polar stratospheric temperature increase of about $25 \mathrm{~K}$ at $10 \mathrm{hPa}$, whereas the lower stratospheric temperature changes at 30 and $70 \mathrm{hPa}$ were much smaller. After circa 20 days the next SSW occurred over the Arctic region. We 
a)

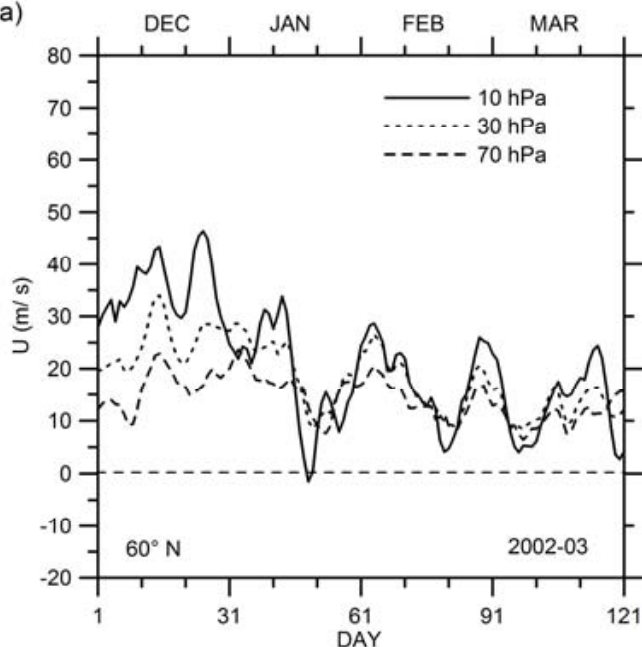

b)

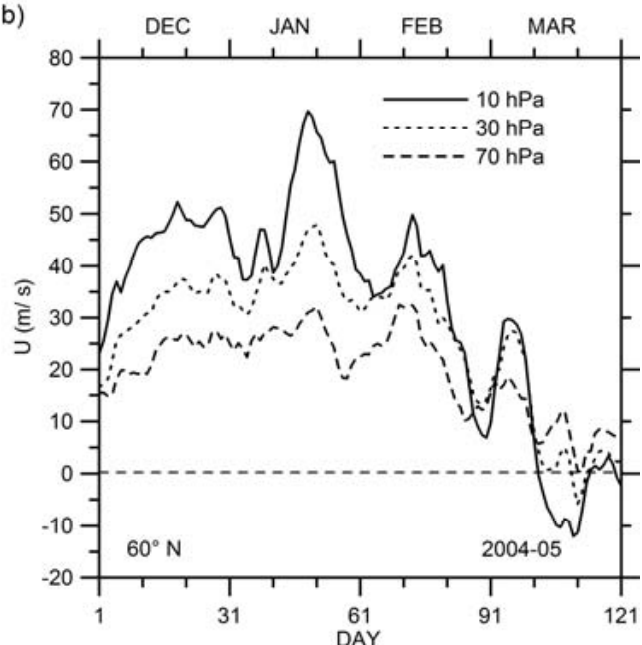

Fig. 3. Zonal mean zonal wind $\left(\mathrm{m} \mathrm{s}^{-1}\right)$ at $60^{\circ} \mathrm{N}$ at 70,30 and $10 \mathrm{hPa}$ from 1 December to 31 March (a) winter 2002-2003 and (b) winter 2004-2005.

can demonstrate that this is a major warming event with a polar temperature increase of about $30 \mathrm{~K}$ for a polar cap of $80^{\circ} \mathrm{N}$. The positive phase has nearly identical periods (longer than a week) for different polar temperature gradients (one is shown in Fig. 4). The wind reversal at $10 \mathrm{hPa}$ lasts for one day (18 January) at $60^{\circ} \mathrm{N}$ and for two days at $65^{\circ} \mathrm{N}$ at $10 \mathrm{hPa}$. The Berlin stratospheric group identified this event as a major warming event in agreement with WMO definition (Labitzke and Naujokat, 2000), but it was not included in the analysis of Harada et al. (2010) because they considered it a less pronounced major warming. Note that the major SSW accompanied an interesting vortex splitting that has not yet been studied. This major SSW leads to a large polar temperature increase of about $18 \mathrm{~K}$ in the middle and lower polar stratosphere (Fig. 2). The reversal of the zonal mean zonal wind towards weak easterlies extends down to $10 \mathrm{hPa}$ at $60^{\circ} \mathrm{N}$ on 18 January (Fig. 3). This major SSW was followed by two relatively weak SSW events at the end of January and beginning of February 2003 which produced weaker zonal mean polar temperature increases (below $10 \mathrm{~K}$ ) and no zonal mean easterlies below $10 \mathrm{hPa}$ at $60^{\circ} \mathrm{N}$. Two further SSWs appeared in mid-February and at the beginning of March. For these SSWs a lower stratospheric temperature increase on the order of about $10 \mathrm{~K}$ was observed with a related weakening of the zonal mean westerlies as expected. The final SSW at the end of March 2003 completed the wintertime circulation over the northern extratropics.

Winter 2004-2005 was chosen for a comparison with winter 2002-2003 because it was characterized by one of the coldest mean polar temperatures in the lower stratosphere (Fig. 2b). Mean temperatures between 195 and $205 \mathrm{~K}$ were observed in the lower stratosphere until almost midFebruary, allowing for significant polar stratospheric clouds (PSCs) to be formed locally. The warming period in the lower stratosphere started in the second half of February. A

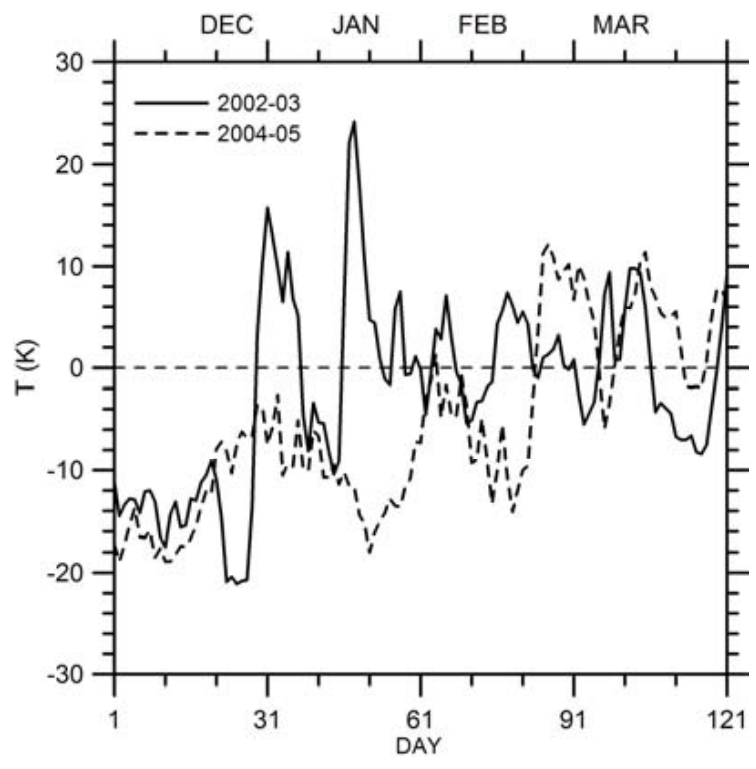

Fig. 4. Meridional gradient of zonal mean temperature $(\mathrm{K})$ between $60^{\circ} \mathrm{N}$ and $90^{\circ} \mathrm{N}$ at $10 \mathrm{hPa}$ from 1 December to 31 March of winters 2002-2003 and 2004-2005.

SSW at the beginning of February leads to a temperature increase of about $10 \mathrm{~K}$ in the middle stratosphere, but shows a weaker increase in the lower stratosphere. This SSW was followed by a SSW event at the end of February which had a temperature increase of about $15 \mathrm{~K}$ in the middle stratosphere and of about $10 \mathrm{~K}$ in the lower stratosphere.

For January and February, Fig. 2 shows that the mean temperature of the lower stratosphere for winter 2004-2005 was colder by about $10 \mathrm{~K}$ than for winter 2002-2003, and a lower variability was observed due to six SSWs in winter 20022003. 


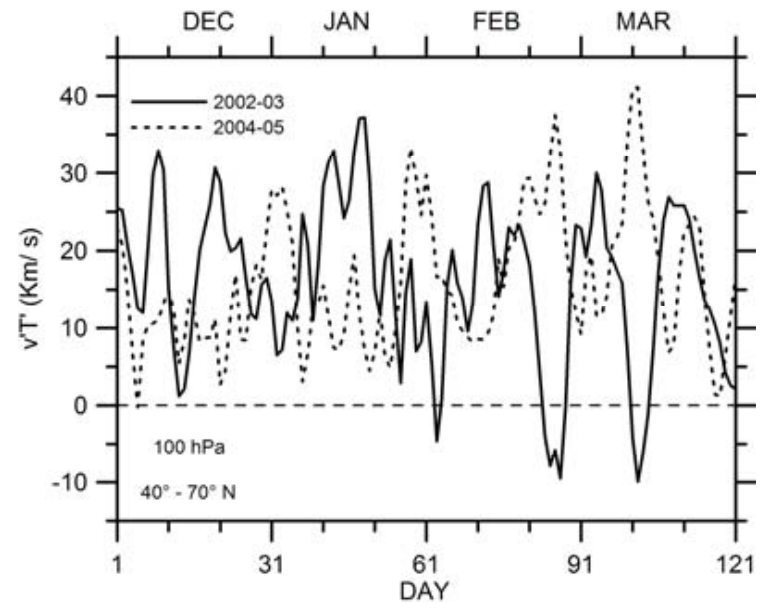

Fig. 5. Zonal mean meridional heat flux $\overline{v^{\prime} T^{\prime}}\left(\mathrm{K} \mathrm{m} \mathrm{s}^{-1}\right)$ at $100 \mathrm{hPa}$ averaged over the latitudinal belt $40^{\circ}-70^{\circ} \mathrm{N}$ from 1 December to 31 March of winters 2002-2003 and 2004-2005.

There was also a significant difference in the zonal mean circulation between these two winters. The evolution of the zonal mean zonal wind at $60^{\circ} \mathrm{N}$ from December 2002 to March 2003 is plotted in Fig. 3. Six main reductions of zonal mean zonal wind occurred in the 2002-2003 winter interrupted by strong westerlies. Note that a weak zonal mean circulation of the Arctic stratosphere with a strong wind decrease during early winter 2002-2003 is contrasted to relatively strong westerlies (vortex) in the mid-winter phase of 2004-2005.

From Fig. 3 (zonal mean zonal wind) and Fig. 4 (zonal mean polar temperature gradient) we conclude that both criteria for a major SSW were fulfilled only on 18 January 2003. Firstly, the reversal of zonal mean zonal wind from westerly to easterly was seen at $60^{\circ} \mathrm{N}$, and secondly the meridional gradient of zonal mean temperature between the Pole and $60^{\circ}$ latitude was positive at $10 \mathrm{hPa}(\sim 32 \mathrm{~km})$ for more than 10 days. In winter 2004-2005 the final warming has already started on 10 March.

The evolution of the zonal mean meridional heat flux is shown in Fig. 5 at $100 \mathrm{hPa}$ for both winters. It is known that $\overline{v^{\prime} T^{\prime}}$ is a proxy for the vertical component of the E-P flux and is used to characterize the intensity of upward planetary wave propagation from the troposphere over middle and high latitudes (e.g., Newman et al., 2001). In winter 2002-2003 a higher variability than in 2004-2005 was found as expected. Furthermore, the strongest heat fluxes of winter 2002-2003 appeared before SSWs. In December of winter 2002-2003 the heat flux was larger than the 2004-2005 winter. Note that the largest values of $\overline{v^{\prime} T^{\prime}}$ were observed some days before the major SSWs in January 2003 and the final warming in mid-March 2005 as expected, indicating that planetary wave propagation from the troposphere to the stratosphere contributed to the major warming (Matsuno, 1971).
The variability of ultra-long waves in the middle stratosphere and in the upper troposphere was examined, which are known to play a dominant rule in the interaction with the zonal mean zonal wind (Holton and Mass, 1976), during both boreal winters. Figure 6 displays the evolution of amplitudes of planetary waves with zonal wave number 1,2 , and 3 from 1 December to 31 March. The selected belt of latitudes $40^{\circ}-$ $75^{\circ} \mathrm{N}$ corresponds to a region of high wave activity.

A large increase followed by a decrease of wave 1 in the middle stratosphere and upper troposphere was observed in December 2002 (Fig. 6a-b). This increase of wave 1 was accompanied by a decrease of wave 2 and 3 . In January, the wave-1 amplitude increased strongly again and this increase was followed by a relatively strong amplification of wave 2 and 3 during the decrease-phase of wave 1, especially during the major SSW event in January 2003. Note that the anticorrelation of wave- 1 and wave- 2 amplitude is often observed during such major warming events (Labitzke and Naujokat, 2000). The increase of wave 1 leads to a modification of the polar vortex shape and a shift of its location away from the Pole. The strong wave-2-increase resulted in a vortex splitting (e.g., McIntyre, 1982; Charlton and Polvani, 2007). The possible cause of vortex splitting in the lower stratosphere will be investigated in more detail in the next section. A similar event was observed in February but with smaller amplitudes of a minor warming event which includes a vortex splitting also. At $300 \mathrm{hPa}$ the amplitude of wave 2 was very large in comparison to wave 1 for February and early March.

In December of winter 2004-2005 the intensity of ultralong wave 1 was weaker in the middle stratosphere (not shown) than in winter 2002-2003 (Fig. 6a). The amplitude increased strongly at the beginning of January but its relative maximum was reached at the end of February. A stronger anticorrelation between wave 1 and 2 was observed in the middle stratosphere during December and at the beginning of January. There was no significant increase of wave 2 in the upper troposphere from January until March as it was observed in 2003 (Fig. 6b).

It is known that planetary wave activity strongly influences stratospheric temperature and circulation over the Arctic and over the Antarctica and hence also the intensity of chemical destruction of the ozone layer during the winter-spring season. In order to determine the impact of these boreal winters the mean chemical ozone loss was estimated following the method employed in Tsvetkova et al. (2007). A significant difference for the polar stratosphere between both examined winters was found as expected. Inside the polar vortex the total ozone loss over the whole winter season amounted to $45.1 \pm 4.3 \mathrm{DU}$ in $2002-2003$ and $116 \pm 10 \mathrm{DU}$ in 2004-2005 which is about 2.5 times larger. Above we mentioned the coherent behavior of changes in northern hemispheric ozone and temperature, forced by wave-driven circulation and eddy mixing, and we mentioned the fact that the ozone-temperature interaction enhances the ozone losses and temperature decreases. In this context we assume that the 

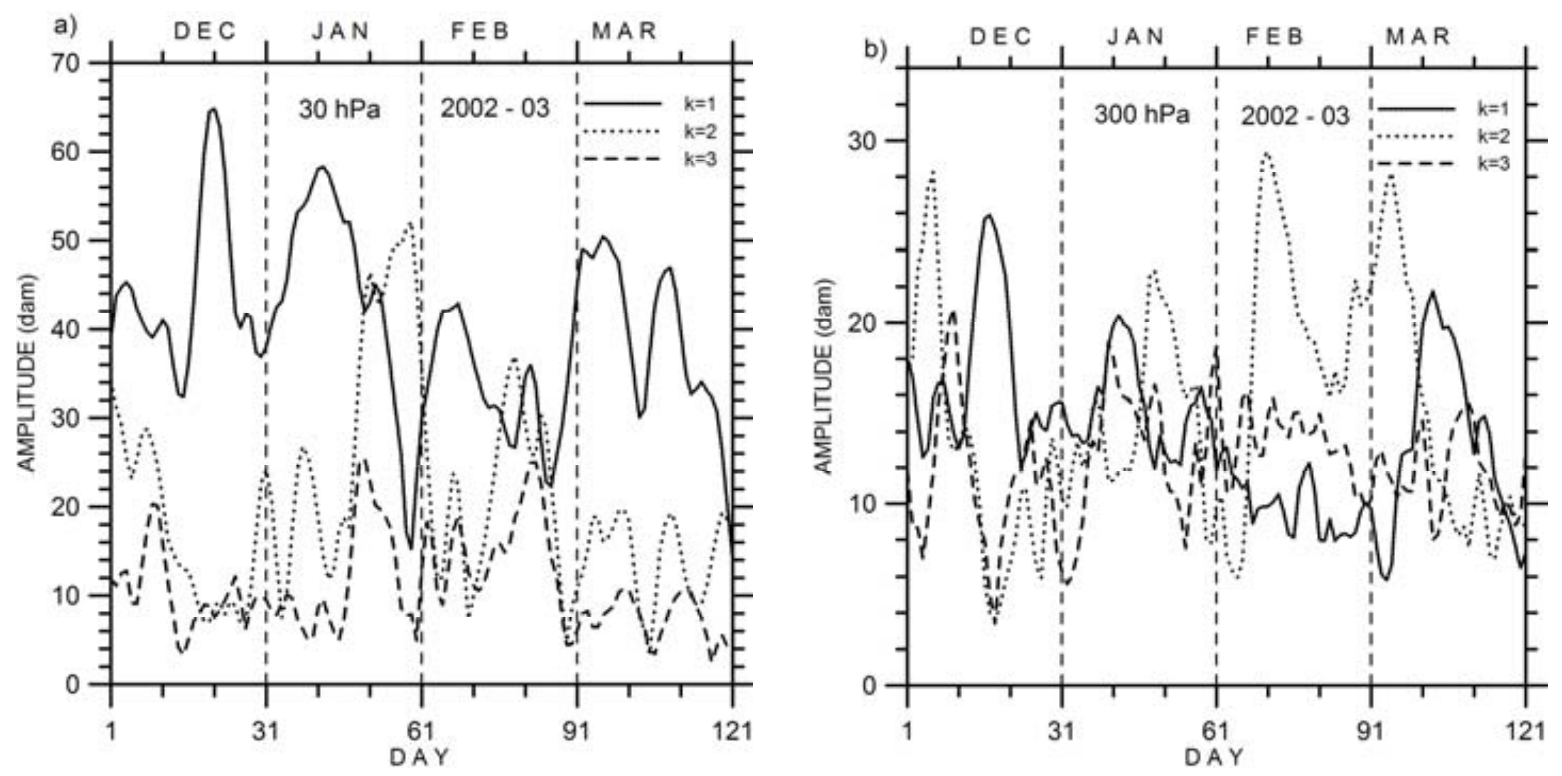

Fig. 6. Amplitude of planetary waves with zonal wave numbers $k=\{1,2,3\}$ in geopotential height (dam) at $30 \mathrm{hPa}(\mathbf{a})$ and at $300 \mathrm{hPa}$ (b) averaged over the latitudinal belt $40^{\circ}-75^{\circ} \mathrm{N}$ from 1 December 2002 until 31 March $2003(\mathrm{a}, \mathrm{b})$.

cooling due to the strong ozone loss during 2004-2005 may have damped waves propagating towards lower stratospheric polar vortex regions, therefore enhancing the strength, stability and lifetime of the polar vortex and decreasing the variations in wave activity during the winter period 20042005. Also, the cooler vortex in winter 2004-2005 was linked to more PSCs than in winter 2002-2003. Therefore the larger ozone losses during February/March 2005, related to heterogenous chemistry on PSC surfaces and activation of chlorine compounds by photochemistry during polar sunrise, may have contributed to the colder temperatures and to the stability of the polar vortex during late winter/early spring. Note here that these considerations would be consistent with the interannual variations in ozone, temperature and planetary wave activity found by Shindell et al. (1997). However, a detailed analysis of these complex interactions requires additional model studies for the specific winter periods and is beyond the scope of this paper.

\section{Tropospheric forcing processes of the major SSW in mid-January 2003}

Regions with enhanced convection in the tropics or subtropics can be detected by analysis of OLR data as negative anomalies from the climatological mean. That means negative anomalies of OLR can be used to localize patterns with increased divergence in the tropopause region. The possible link to Rossby wave generation was discussed for instance by Hoskins and Karoly (1981) or Sardeshmukh and Hoskins (1988). Furthermore, we want to show that this wave could propagate northwards and maintain a blocking high in the upper troposphere, which may be important for the generation of the major SSW on 17-18 January 2003 due to strong vertical planetary wave fluxes.

Note that for the major SSW over Antarctica in September 2002 it was already shown that for 10-14 days the wave trains transferred energy from the subtropics to higher latitudes (e.g., Nishii and Nakamura, 2004; Peters et al., 2007).

The OLR anomalies were calculated as anomalies from corresponding climatological means over the period 19791995. Figure 7 displays the OLR anomalies for a region including a latitudinal belt from the equator to $40^{\circ} \mathrm{N}$ averaged over three periods of 5-days from 27 December 2002 until 11 January 2003. Two main regions with strong negative OLR anomalies in a latitudinal belt from equator to $20^{\circ} \mathrm{N}$ were identified in Fig. 7 which indicate regions of high upper tropospheric divergence. Over the Indian Ocean/south-eastern Asia region $\left(90^{\circ}-120^{\circ} \mathrm{E}\right)$ the OLR anomaly decreased in time. Over the central-eastern Pacific Ocean region $\left(120^{\circ}\right.$ $90^{\circ} \mathrm{W}$ ) a relative minimum increased until the 7-11 January period.

The region with negative OLR anomalies over the centraleastern Pacific may be caused by positive anomalies of sea surface temperature (SST). This region with negative OLR anomalies can be seen in the monthly averages as well (not shown). However, the strongest convection and rainfall were observed near the date line in January 2003 (McPhaden, 2004). The second region with negative OLR anomalies over the Indian Ocean/south-eastern Asia also corresponds to positive anomalies of SST. Our analysis showed that this deep convection region developed over the central Indian Ocean at the beginning of December and propagated eastwards. 
a) 27-31 DEC 02

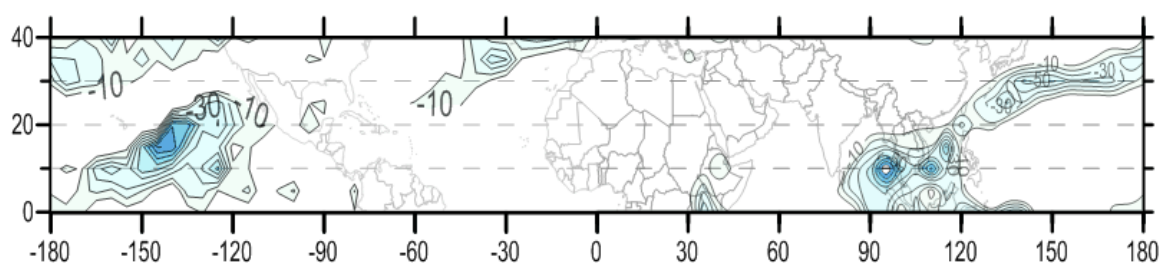

b) 1-5 JAN 03

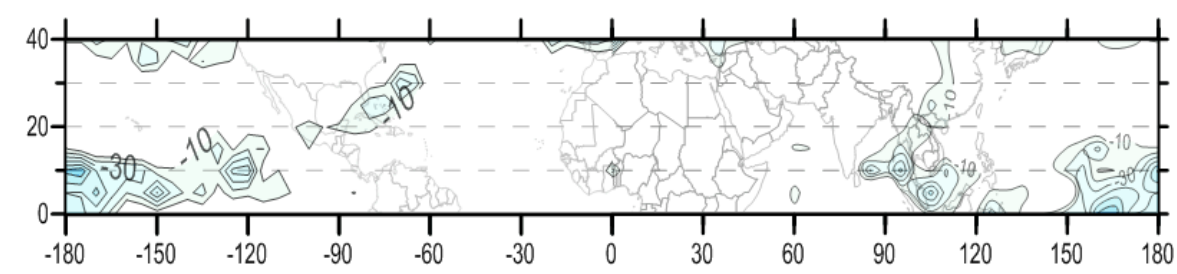

c) 7-11 JAN 03

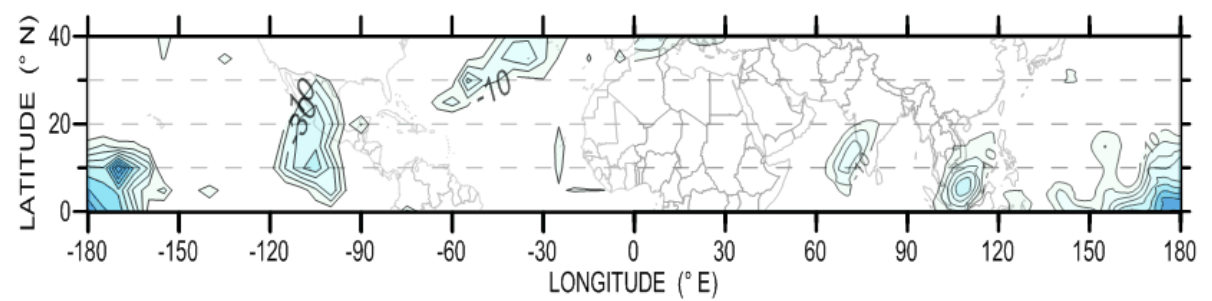

Fig. 7. Longitudinal anomalies of OLR $\left(\mathrm{W} / \mathrm{m}^{2}\right)$ in latitudinal belt from $0^{\circ}$ until $40^{\circ} \mathrm{N}$ averaged over the period $27-31 \mathrm{December} 2002($ a), 1-5 January (b) and 7-11 January 2003 (c). Only negative anomalies are plotted indicating upper tropospheric divergence.

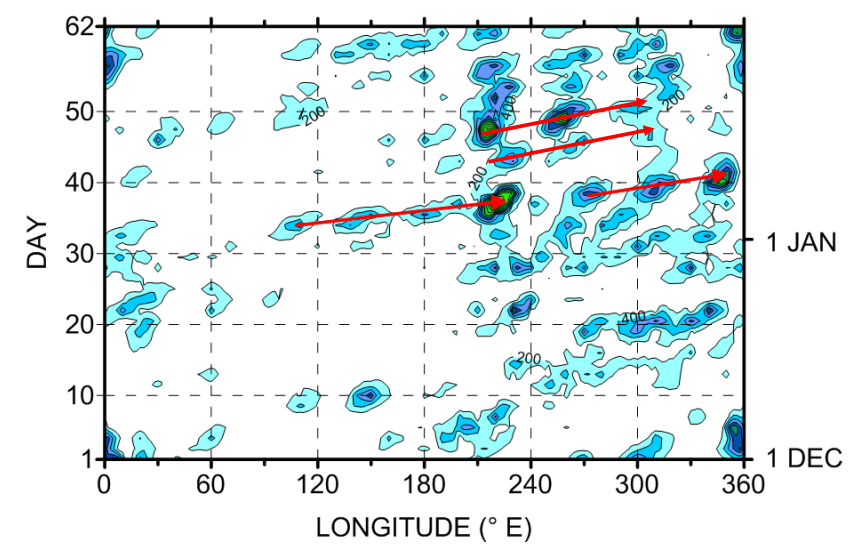

Fig. 8. Hovmöller diagram of the squared velocity of meridional wind $\left(\mathrm{m}^{2} \mathrm{~s}^{-2}\right)$ from 1 December 2002 until 31 January 2003 averaged over a latitudinal belt $\left(30^{\circ}-50^{\circ} \mathrm{N}\right)$ at $300 \mathrm{hPa}$. Contours are smoothed with a Gaussian filter and start at $200 \mathrm{~m}^{2} \mathrm{~s}^{-2}$ with an interval of $200 \mathrm{~m}^{2} \mathrm{~s}^{-2}$. Arrows indicate direction of group velocity of four revealed Rossby-wave trains.

Further investigation of the possible causes of generation and eastward propagation of this OLR anomaly are beyond the scope of this study.
As in Peters et al. (2007) we analyzed squared velocity of meridional wind in the middle and upper troposphere to reveal possible Rossby wave trains and to analyze their propagation. Figure 8 shows the longitude-time cross section of squared velocity of the meridional wind from 1 December 2002 to 31 January 2003 averaged over a latitudinal belt from $30^{\circ}$ to $50^{\circ} \mathrm{N}$ at $300 \mathrm{hPa}$.

Two strong wave trains can be identified clearly in the upper troposphere over northern midlatitudes at the beginning of January (Fig. 8). A wave train started on 2-4 January in the longitude range, $90^{\circ}-120^{\circ} \mathrm{E}$, and the second one a couple of days later on 5-7 January in the region of $250^{\circ}-280^{\circ} \mathrm{E}$. Note that both these regions of Rossby wave generation are consistent with regions of enhanced deep convection showed before, allowing a 10 degrees variability (Fig. 7).

It is known that the group velocity of wave trains is parallel to wave energy propagation. In Fig. 8 these directions are indicated by four arrows. That means that these two Rossby wave trains extended eastwards and transferred wave energy to higher northern latitudes from the subtropics where the source of transient wave energy was found (Fig. 7).

A couple of days later but just before and during the major SSW we identified two further wave trains over the Eastern Pacific - North America region. In contrast to the subtropical 

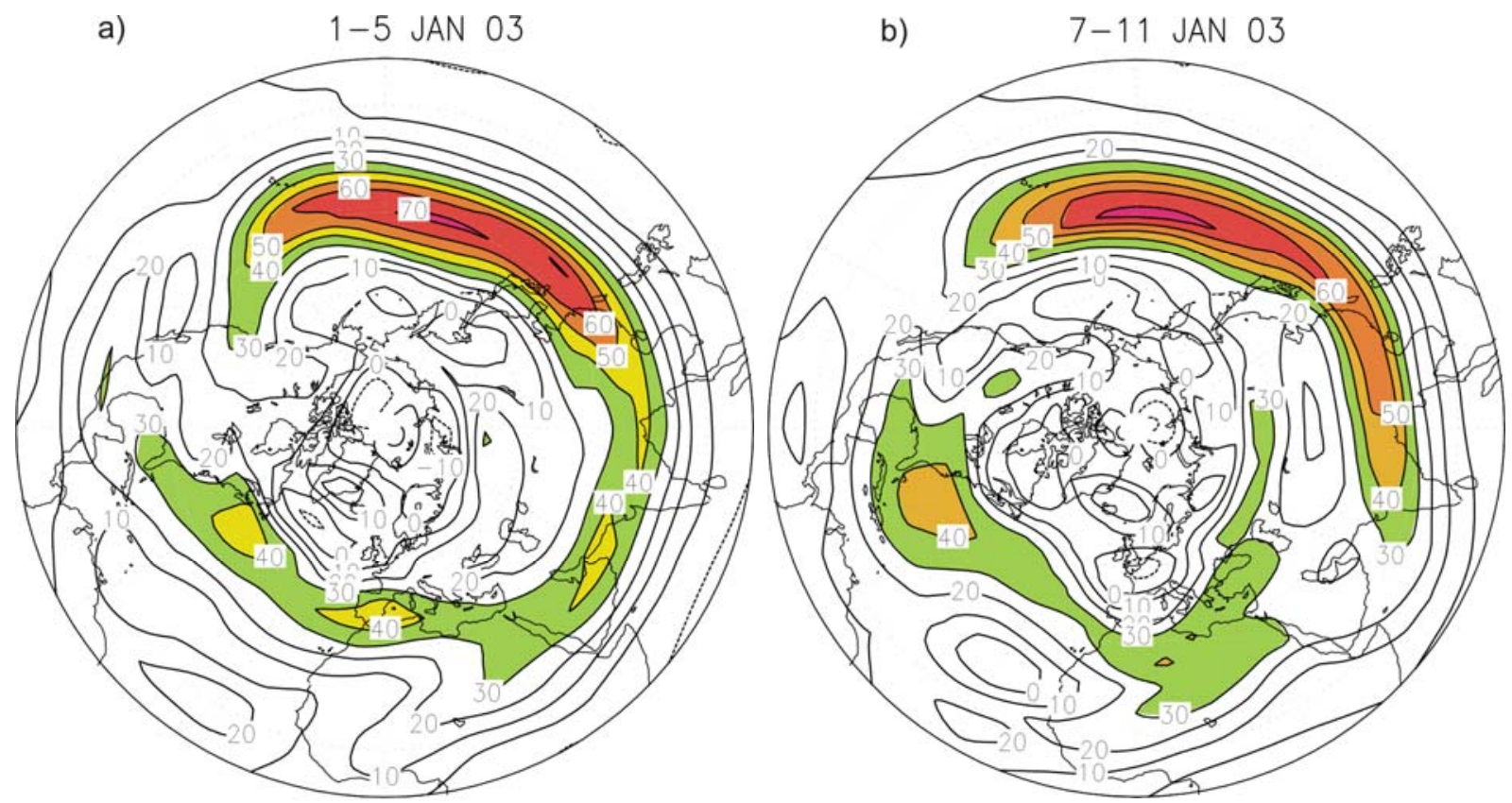

Fig. 9. Stereographic projection of the zonal wind at $300 \mathrm{hPa}$ for the period $1-5$ (a) and 7-11 January 2003 (b). Values $>30 \mathrm{~m} \mathrm{~s}^{-1}$ are colored.
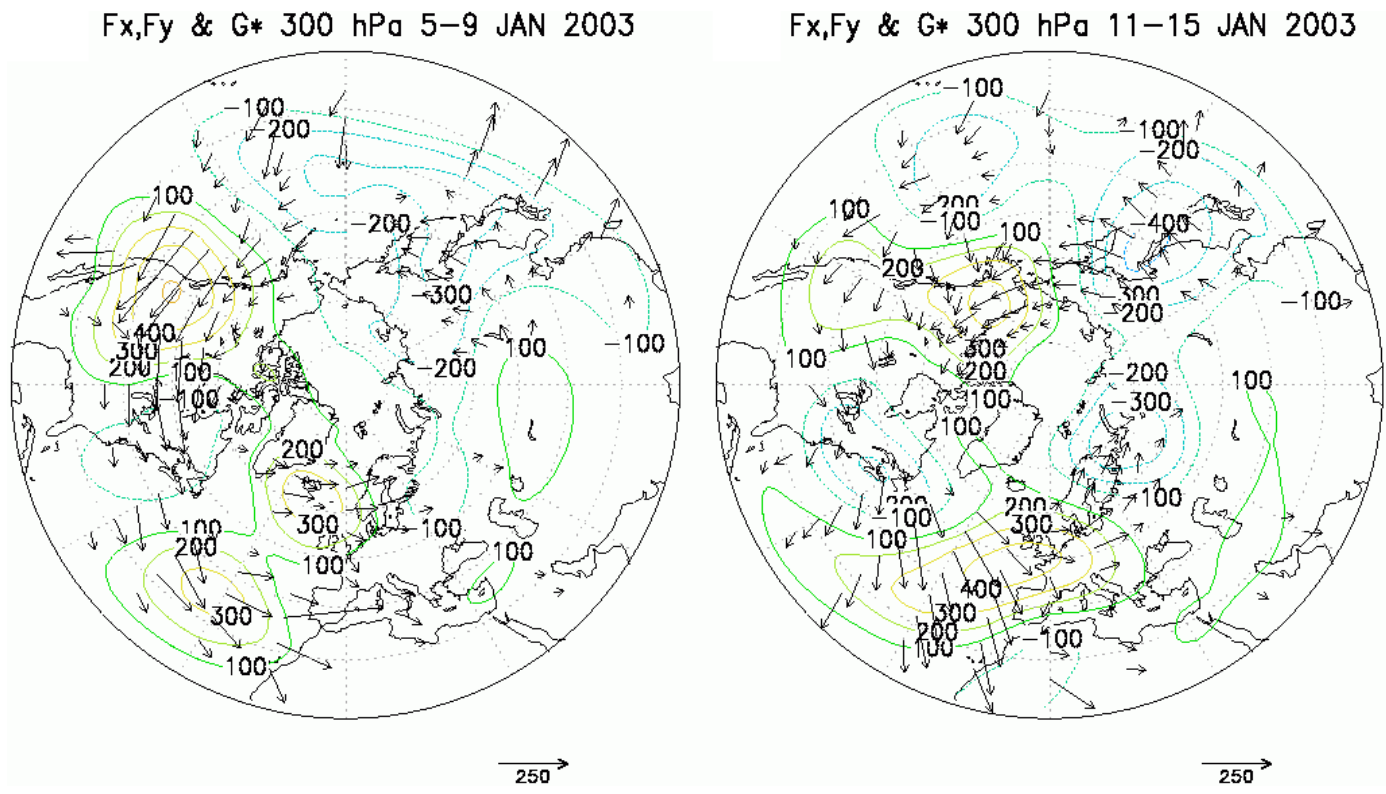

Fig. 10. Stereographic projection of geopotential height perturbation $G^{*}\left(\right.$ dam) and horizontal Plumb flux vector $\left(\mathrm{m}^{2} \mathrm{~s}^{-2}\right)$ at $300 \mathrm{hPa}$ for the period 5-9 (left) and 11-15 January 2003 (right).

wave trains, these wave trains started in the middle latitudes of the central Pacific Ocean and propagated along a northerly pathway as we will show below.

For the Pacific wave train, the subtropical jet with more than $30 \mathrm{~m} \mathrm{~s}^{-1}$ (Fig. 9a) represents the upper tropospheric wave guide in which the Rossby wave can propagate from its region of generation (eastern Indian Ocean) to its break- ing region over the eastern Pacific Ocean. It took a couple of days before the transient Rossby wave packet reached the ridge over the Rocky Mountains (Fig. 10, left) where it contributed to the maintenance of the anticyclone, as shown for a similar case by Shutts (1983). A similar but weaker and shorter wave guide was found a couple of days later over the North Atlantic during 7-11 January (Fig. 9b). 
a) 1-5 JAN 03

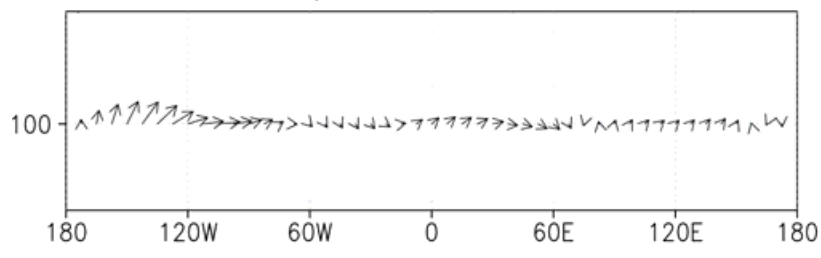

b) $5-9$ JAN 03

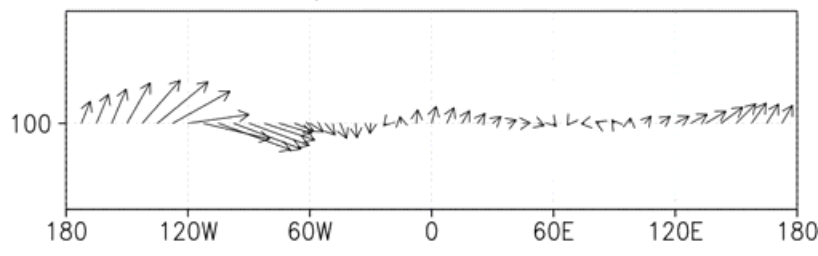

c) $9-13$ JAN 03

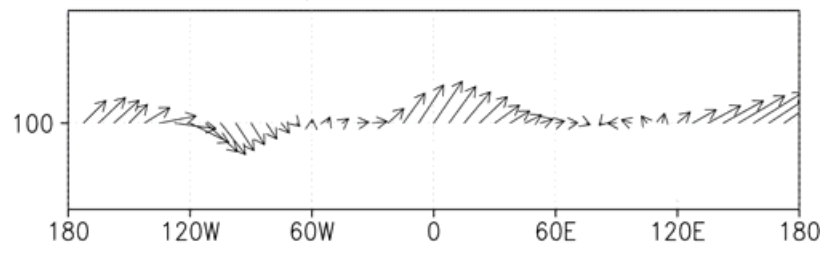

d) 13-17 JAN 03

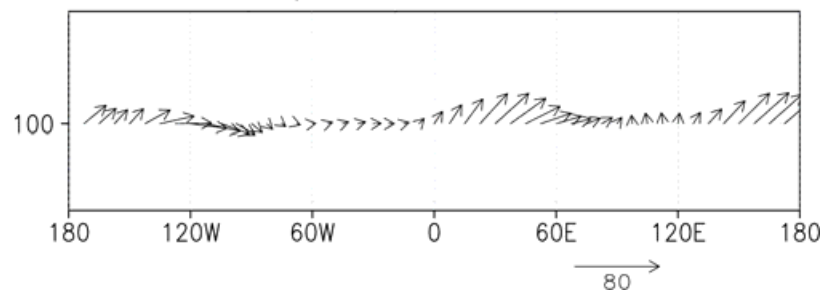

Fig. 11. Altitude-longitude cross-section of mean Plumb flux vector $\left(\mathrm{m}^{2} \mathrm{~s}^{-2}\right)$ at $100 \mathrm{hPa}$ averaged over the latitudinal belt $40^{\circ}-60^{\circ} \mathrm{N}$ based on 5-day means for the 1-17 January-period. The scale factor of the fluxes is 80 as indicated by the arrow below the last panel. The vertical component of wave activity flux is multiplied by a factor of 100 .

From its subtropical forcing region over the central-eastern Pacific Ocean the Rossby wave packet propagated northeastwards over the North Atlantic, where it broke and due to that wave breaking process maintained the anticyclone over western Europe for some days later (Fig. 10, right). At the same time, another wave train occurred but was located over the extratropical region of North America also shown in Fig. 10 (right). A similar wave train was already identified in Fraedrich et al. (1993) where they discussed this northern path of atmospheric influence from the Pacific Ocean on upper tropospheric processes over the polar region of the North Atlantic. In particular, this could have a large impact on the Grosswetterlage over northern Europe. The mean geopotential perturbation structure of the upper troposphere in Fig. 10 (right) captured parts of both wave trains running from the central Pacific Ocean over polar North America to the North Atlantic region.

The induced stratospheric wave activity forced by these wave trains has been analyzed by the calculation of the horizontal Plumb flux vector at $300 \mathrm{hPa}$ (Fig. 10) and verticalzonal flux vector at $100 \mathrm{hPa}$ (Fig. 11). The horizontal Plumb flux is mostly directed to the East in the upper tropopause region. Strong fluxes are found during the 5-9 January-period over the eastern Pacific and North America and over the eastern North Atlantic but with a weaker equatorward component of the Plumb flux. Later, for the 11-15 January-period, the flux over the eastern North Atlantic amplified and split up into a northward and southward directed flux vector.

Figure 11 illustrates those Plumb fluxes in midlatitudes averaged between $40^{\circ}-60^{\circ} \mathrm{N}$ for 5 -day periods during the beginning of January 2003. On 5-9 January a strengthening of planetary wave propagation from troposphere to stratosphere occurred over the eastern Pacific Ocean. This strengthening was characterized by an increase of the horizontal and vertical component of Plumb flux. Several days later a weakening was observed over the Pacific ocean accompanied by an increase of the vertical wave activity over the eastern North Atlantic-European region $30^{\circ} \mathrm{W}-60^{\circ} \mathrm{E}$ (Fig. 10 (right) and Fig. 11c, d). Just before the major warming event we found two regions with enhanced tropospheric forcing in Fig. 11d, which are in good agreement with the two anticyclones shown in Fig. 10 (right) at $300 \mathrm{hPa}$ (but for a two day backward shifted period).

During the first two weeks of January 2003 our calculation of the vertical Plumb flux in the middle stratosphere at $30 \mathrm{hPa}(\sim 25 \mathrm{~km})$ revealed a similar behavior (not shown) to that found in the lower stratosphere with a relative strengthening of the vertical wave activity flux first over the eastern Pacific Ocean and later over the eastern North Atlantic.

Before we continue with a further diagnosis of the zonal behavior of wave activity fluxes the EP flux (defined as the zonal average of the Plumb flux vector) is shown as a reference for the change of the mean zonal state in Fig. 12. In the pre-warming phase of the major SSW event (13-17 January) the EP flux is directed upward and eastward in low latitudes and contributed to the acceleration of the subtropical jet. In higher latitudes the flux is directed upward and slightly northwards before it turned southward in the middle stratosphere to cause the acceleration of the polar night jet. During the 17-21 January-period the amplified EP flux in higher latitudes is directed to the North in the upper troposphere and lower stratosphere, causing a deceleration of the zonal mean zonal wind in the middle and upper stratosphere with a wind reversal to easterlies over polar latitudes.

A more detailed diagnosis of the longitudinal evolution of wave activity fluxes before and during the major warming event is presented in Fig. 13. Due to the fast development of this major warming event we are showing 3 day steps of 3 day-mean states from 10 until 19 January averaged between $50^{\circ}$ and $70^{\circ} \mathrm{N}$. 

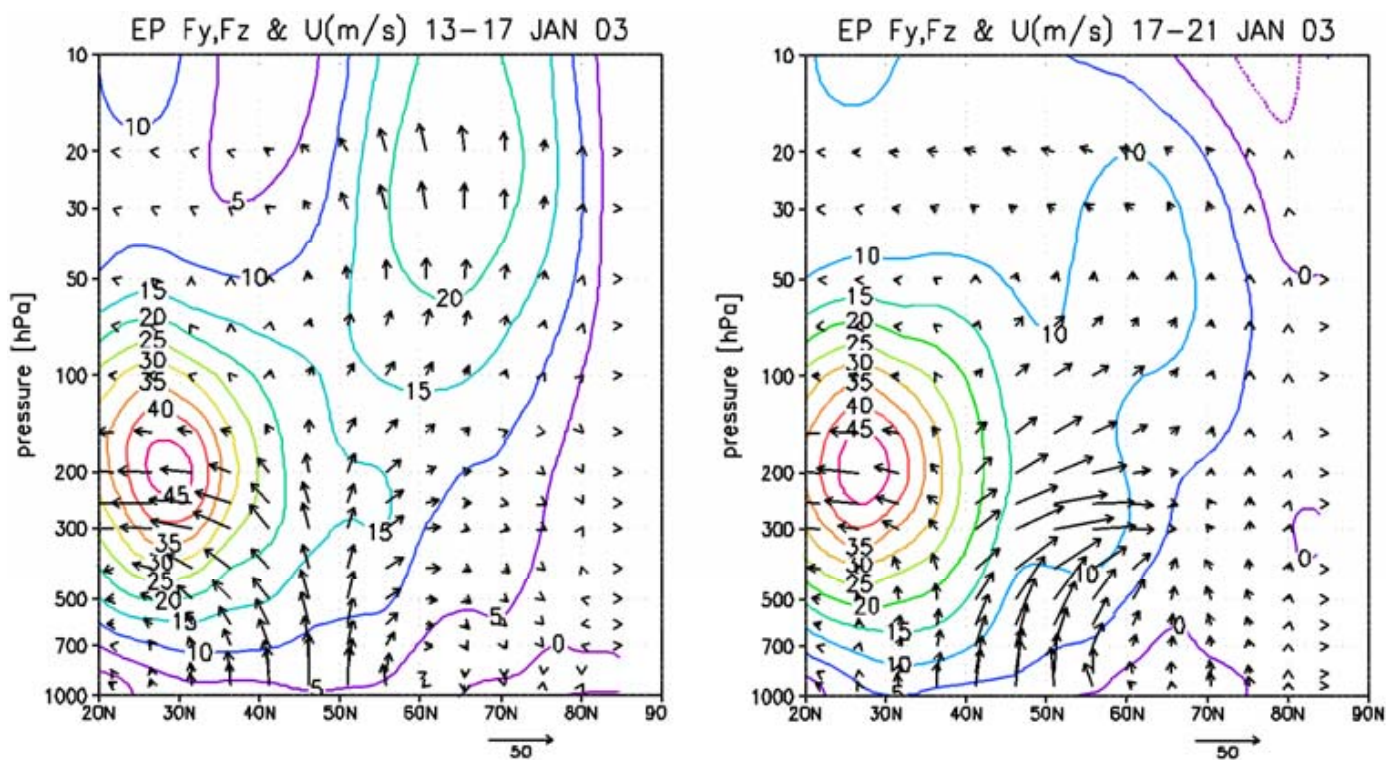

Fig. 12. Height-latitude cross section of E-P flux $\left(\mathrm{m}^{2} \mathrm{~s}^{-2}\right)$ and zonal mean zonal wind $\left(\mathrm{m} \mathrm{s}^{-1}\right)$ averaged from 13-17 January (left panel) and 17-21 January (right panel) of 2003. The vertical component of EP-flux is multiplied by a factor of 100.

For day 10 (Fig. 13a) the polar vortex was located over the North Atlantic European region as part of a well developed wave number 1 structure. The accompanying ridge showed only a weak westward phase shift with increasing altitude and reached the upper troposphere over the Rocky Mountains as also indicated in Fig. 10. The second strong anticyclone in Fig. 13a occurred over the North Atlantic-European region. This high was also identified in Fig. 10. Both upper tropospheric anticyclones have been related to subtropical Rossby wave trains (Fig. 8). In Fig. 13a we found that in connection with these two anticyclones a strong upward and eastward Plumb flux occurred only over the Eastern North Atlantic which reached the middle stratosphere. The wave activity flux over the Eastern Pacific Ocean showed a stronger refraction in the lower stratosphere. This resulted in a decrease of vertical wave activity fluxes over the next several days as shown in Fig. 11. This process continued over the next 3 days (Fig. 13b) with a weakened anticyclone on day 13. During that time the North Atlantic ridge strengthened and shifted slightly eastward. But three days later due to the action of the extratropical Rossby wave train the Plumb flux over the eastern Pacific Ocean increased again. This increase caused a strong disturbance of the polar vortex due to an additional decrease of geopotential height over North America (Fig. 13c) on day 16. This decrease continued over 3 days due to the action of the next extratropical wave train shown in Fig. 8 and indicated in Fig. 10 so that a very strong cyclonic perturbation developed very fast over eastern North America and over the western North Atlantic. From a zonal mean point of view, the deposition of easterly angular momentum in the stratosphere due to the divergence of planetary wave activity fluxes caused the strong deceleration of the zonal mean zonal wind and the sudden major warming as we know from Matsuno's theory (Matsuno, 1971). From a zonally asymmetric point of view, the vertical wave activity fluxes over Central Europe are still strong enough to maintain a cut off low over Eastern Europe in the lower and middle stratosphere. As a result the polar vortex was divided into two parts. This vortex splitting is mainly related to the tropospheric forcing of different Rossby wave trains.

A further investigation of the coherent development down to the troposphere during the splitting process of the major SSW was carried out. A lag-correlation analysis was applied to a reference point over Canada $\left(90^{\circ} \mathrm{W}, 60^{\circ} \mathrm{N}\right)$ at $30 \mathrm{hPa}$ where the second polar vortex occurred and amplified. The results are shown in Fig. 14 for different time lags of $(-4$, $-2,0,3)$ days.

With a lag of -4 days we found a significant correlation which started in the troposphere over the Eastern Hemisphere and propagated upward into the stratosphere indicating two centers over Canada and Siberia (left panel Fig. 14a). This coherent structure could already be seen 4 days before the development of the wave group with a zonal wave number 2 in the stratosphere and troposphere as shown in Fig. 14b (upper two panels). The other panels of Fig. 14a show the modification of this coherent structure for a lag-correlation of $\{-2$, $0,+3\}$ days in detail. An additional amplifying wave train was identified which started over the eastern North Atlantic and propagated eastward and upward into the middle stratosphere as a wave packet with wave number 2 . This wave train maintained the splitting of the vortex by an increase of the polar low over Canada but reduced the coherence of the vortex over Siberia as shown in Fig. 14b (middle and lower panel pairs). The strong upper tropospheric path at $300 \mathrm{hPa}$ 

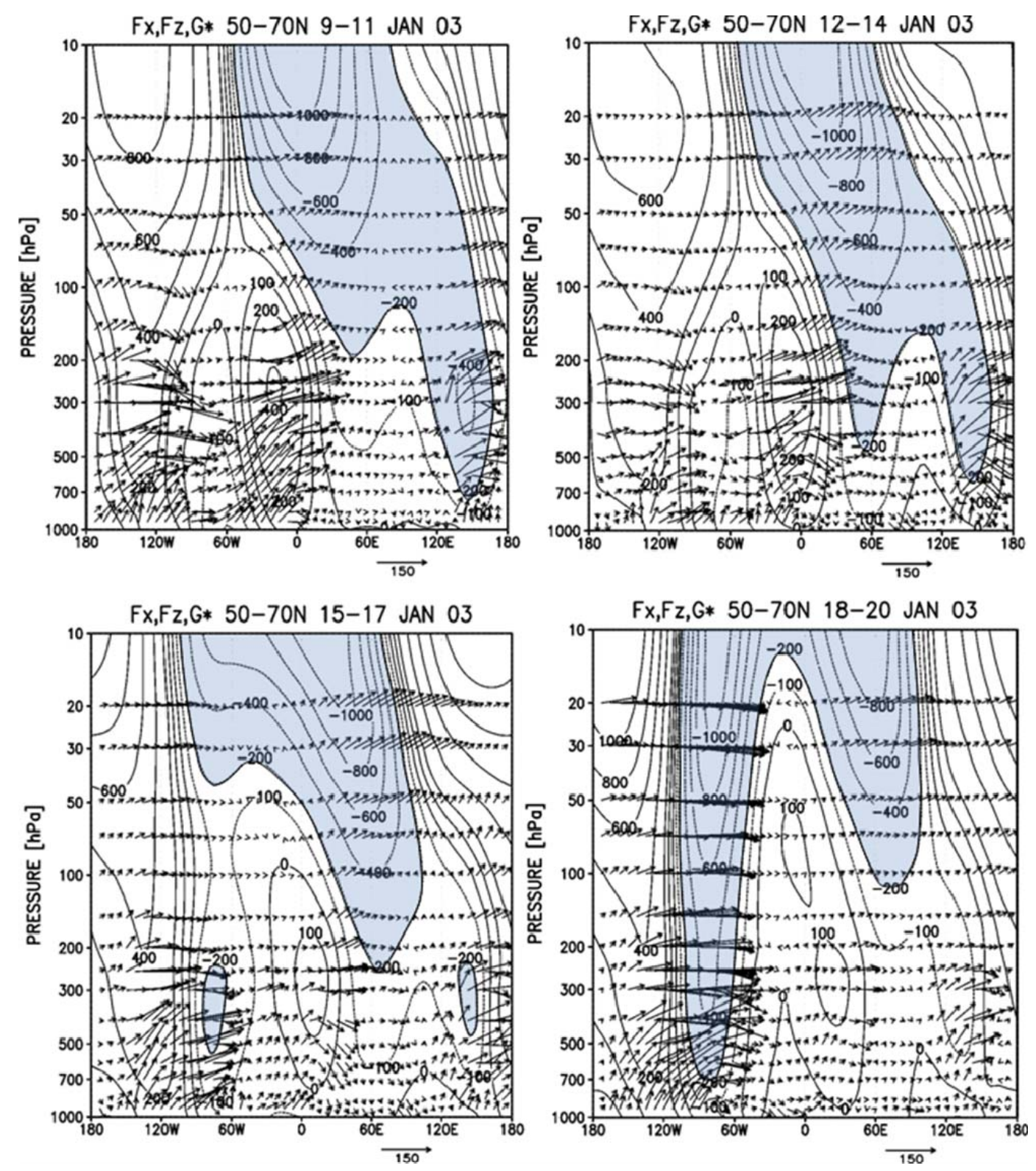

Fig. 13. Altitude-longitude cross-section of geopotential height perturbation $(\mathrm{m})$, negative isolines are dotted; Plumb flux vector $\left(\mathrm{m}^{2} \mathrm{~s}^{-2}\right.$ ) averaged over $50^{\circ}-70^{\circ} \mathrm{N}$ based on 3-day means; 9-11 January 2003 (a), 12-14 January (b), 15-17 January (c), and 18-20 January 2003 (d). The vertical component of Plumb-flux is multiplied by a factor of 100 .

over the northern part of North America is also indicated in Fig. 14b. There exists a strong agreement in the temporal behavior of the results shown in Figs. 13 and 14. Both diagnostics are showing independently the same wave trains.

\section{Discussion and conclusion}

The dynamical evolution of the relatively warm stratospheric winter season 2002-2003 of the Northern Hemisphere was studied and compared with the cold winter 2004-2005 based on NCEP-Reanalysis daily data. Only at the beginning of
2002-2003 winter were record low temperatures observed in the lower and middle stratosphere over Arctic region. Six sudden stratospheric warming events including the major warming event with a splitting of the polar vortex in mid-January 2003 were identified which led to a very high variability of the zonal mean circulation and a weakening of the stratospheric polar vortex over the whole winter season. These results based on NCEP reanalysis data are in good quantitative agreement with standard diagnostics from NWS Climate Prediction Centre: http://www.cpc.ncep.noaa. gov/products/stratosphere/strat-trop/. 
a)

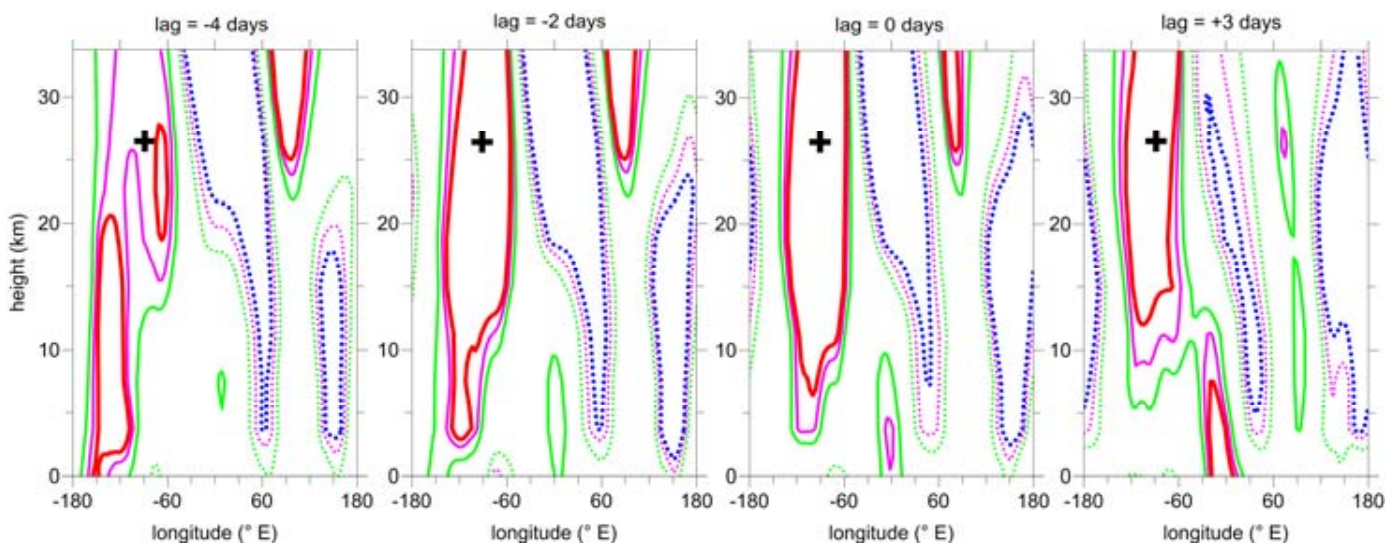

b)
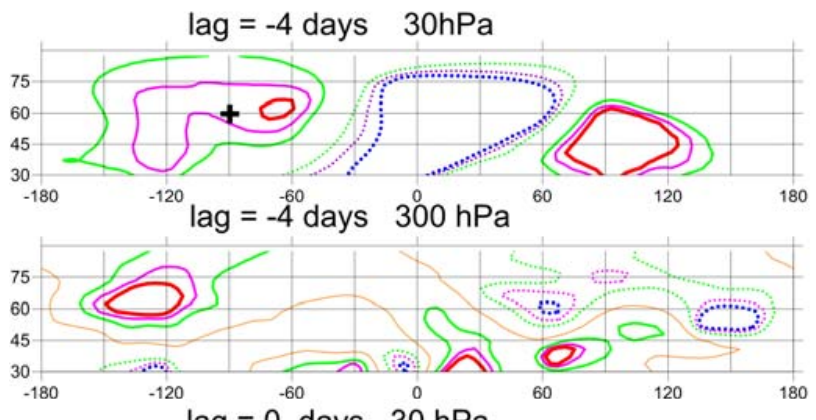

lag $=0$ days $30 \mathrm{hPa}$
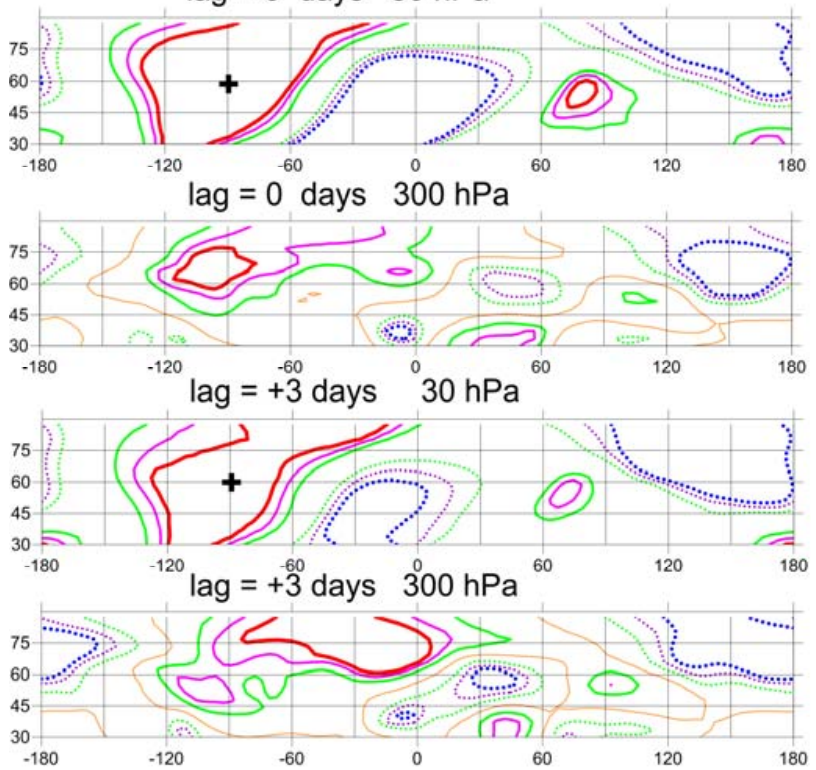

Fig. 14. Lag-correlation of geopotential height anomalies with the reference point $\left(90^{\circ} \mathrm{W}, 60^{\circ} \mathrm{N}, 30 \mathrm{hPa}\right)$ for January 2003 (a) altitudelongitude cross sections at $60^{\circ} \mathrm{N}$ and (b) latitude-longitude cross sections at $30 \mathrm{hPa}$ (upper panel) and $300 \mathrm{hPa}$ (lower panel) for $\{-4,-2$, $0,+3\}$ day lags. Lines are shown for 80,90 and $95 \%$ confidence levels, respectively. The cross marks the position of the reference point $\left(90^{\circ} \mathrm{W}, 60^{\circ} \mathrm{N}\right)$ at $30 \mathrm{hPa}$.

Further the impact of different mean temperatures of Arctic stratosphere was examined by an estimation of the mean total chemical ozone loss inside the polar vortex follow- ing the method employed in Tsvetkova et al. (2007) including ozone-sondes from Salekhard station in northern Russia $\left(66^{\circ} \mathrm{N}, 66^{\circ} \mathrm{E}\right)$. We found a total ozone decrease of about 
45 DU caused by chemical destruction in winter 2002-2003 and about 116 DU in winter 2004-2005. That means that for the cold winter 2004-2005 the total ozone loss was about 2.5 times larger than in winter 2002-2003.

In the winter 2002-2003 high wave activity was observed with relatively low ozone depletion. In comparison the winter 2003-2004 showed less wave activity with relatively high ozone loss. Interannual variations in ozone depletion during winter are linked with variations in tropospheric wave energy which influence the circulation of the whole atmosphere, as indicated by observations and model studies (Randel and Cobb, 1994; Shindell et al., 1997; Randel and Wu, 1999; Gabriel and Schmitz, 2003). Considering these findings we conclude that, in addition to the different forcing from the troposphere described in Sect. 4, the cooling due to the strong ozone loss during 2004-2005 may have contributed to the stability and long lifetime of the polar vortex and, therefore, to the weaker variability of wave activity in the stratosphere during winter 2004-2005.

There are other processes which could also play a dominant role in the extratropical stratosphere ozone and vortex variability in boreal winters like, for instance, the QuasiBiennial Oscillation (QBO). The western phase of QBO during December-January is accompanied often by a colder and more stable polar vortex in comparison to the eastern phase when the polar vortex is usually weaker and less stable. Both boreal winters, 2002-2003 and 2004-2005, are characterized by the western phase of QBO. Therefore we conclude that QBO influence is not important. However, the QBO effect on year-to-year variability of extratropical stratospheric dynamics is not considered further here.

Because each major warming has its own life cycle with different forcing and evolution we focus here on the 2003 major warming because it was embedded in a winter with a high number of sudden stratospheric warming events as mentioned above. In particular the major sudden stratospheric warming event in January 2003 with a polar vortex splitting has been studied in more detail in order to identify different tropospheric forcing processes. In this study we assume that deep convection with reduced OLR could be a signal of a upper tropospheric increase of the divergence which acts as a source of Rossby waves. Furthermore, Li and Fu (2006) showed on the basis of satellite data analysis that due to energy propagation from tropical cyclones the forcing of a Rossby wave could be expected but the generation of wave trains depends on many other factors. The investigation of these generation processes is beyond the scope of this study.

We identified two isolated Rossby wave trains one starting after the other in a region with strong convection over southeastern Asia and over the subtropical central-eastern Pacific Ocean in the beginning of January. We can show that Rossby wave trains extended north-eastwards in strong wind jets $\left(>30 \mathrm{~m} \mathrm{~s}^{-1}\right)$. When the waves finally broke they contributed to the maintenance of two upper tropospheric anticyclones. One week before the major warming event we found an am- plification of these upper tropospheric anticyclones over the Rocky Mountains and over the north-eastern North Atlantic which were accompanied by a regional increase of planetary wave activity flux into the stratosphere. The amplification of an upward propagating planetary wave 2 was observed in the upper troposphere and lower stratosphere. A couple of days later two strong extratropical Rossby wave trains occurred over North America inducing very strong horizontal and vertical planetary wave activity fluxes over the North America North Atlantic region causing a strong intensification of the cyclonic activity over the Labrador region. Finally, the polar vortex broke into two parts with an accompanying sudden stratospheric warming.

There exists a strong agreement in the temporal behavior of the results as shown in Fig. 13 based on Plumb flux diagnostics and in Fig. 14 using a lag-correlation method. Both methods show independently the same wave trains because both are related to energy propagation as indicated by the group velocity vector. The Plumb flux is, in the WKB limit, parallel to the group velocity vector and the significant lagcorrelation patterns indicate wave group velocities also.

In contrast to our findings, Peters et al. (2007) also identified two subtropical Rossby wave trains for the 2002 austral major warming event with a split vortex but both occurred at the same time. Harada et al. (2010) focused in their study on the extraordinary boreal January 2009 major warming event that led also to a polar vortex splitting. They showed the important role of two extratropical planetary wave packets in the evolution of the major SSW event. The first wave packet was observed over the North Atlantic followed by an increasing wave packet over the eastern Pacific Ocean. This wave packet caused a strong cyclonic perturbation over North America due to enhanced vertical and eastward directed planetary wave fluxes into the stratosphere and contributed mainly to the major SSW. Due to induced horizontal wave fluxes the low over Siberia was maintained and amplified, therefore the splitting of the polar vortex was supported. This behavior is similar to the case in January 2003. The strong horizontal planetary wave fluxes found by Harada et al. (2010) were also important in the 2003 major SSW event as shown in Fig. 13c, d.

In summary we concluded that embedded in a winter with high planetary wave activity the major SSW event of January 2003 was caused by the following different tropospheric forcing processes:

1. Two subtropical wave trains occurred before the warming event, one starting behind the other, and the first over the eastern Indian Ocean and the second over the eastern Pacific Ocean.

2. Both Rossby wave trains contributed to the maintenance of two quasi-stationary anticyclones. The evolution of the accompanying planetary wave activity fluxes was different and caused a decrease of the eastern Pacific ridge and increase of the eastern North Atlantic high, 
but accompanied by an increase of wave- 2 amplitude in the upper troposphere.

3. In addition, two extratropical wave trains occurred over North America. The induced planetary wave activity flux caused the increase of the eastern Pacific ridge and last, but not least, the strong cyclonic perturbation over North America due to an eastward and upward propagating wave group from the troposphere. Through zonal mean diagnostics a major sudden warming event was identified for 1-2 days after WMO criteria.

4. Strong planetary wave activity fluxes over Europe enhanced by horizontal fluxes maintained the stratospheric low over Eastern Europe and contributed to the splitting of the polar vortex in the lower and middle stratosphere was caused by the same eastward and upward propagating wave train mentioned under point 3 . The split vortex remained also in the post warming phase as already shown in Fig. 1.

Acknowledgements. NCEP Reanalysis and interpolated OLR data were provided by the National Oceanic \& Atmospheric Administration Climate Diagnostics Centre, Boulder, Colorado, USA. Russian authors thank the Russian Foundation of Basic Research Grant \# 09-05-13551, 10-05-00890. The work of A. Gabriel was supported by German Science Foundation under Grand PE 474/4-2. We thank Christoph Zülicke and two anonymous reviewers for their helpful comments for improving our manuscript. Further we thank Phillip Bracikowski for manuscript editing.

Topical Editor C. Jacobi thanks two anonymous referees for their help in evaluating this paper.

\section{References}

Andrews, D. G., Holton, J. R., and Leovy, C. B.: Middle Atmospheric Dynamics, Academic Press, 489 pp., 1987.

Baldwin, M. P. and Dunkerton, T. J.: Stratospheric harbingers of anomalous weather regimes, Science, 294, 581-584, 2001.

Castanheira, J. M., Liberato, L. R., Marques, C. A. F., and Graf, H.-F.: Bridging the annular mode and the North Atlantic ocscillation paradigms, J. Geophys. Res., 112, D19103, doi:10.1029/2007JD008477, 2007.

Chang, E.: Downstream development of baroclinic waves as inferred from regression analysis, J. Atmos. Sci., 50, 2038-2053, 1993.

Charlton, A. and Polvani, L.: A new look at stratospheric sudden warmings. Part I: Climatology and modeling benchmarks, J. Climate, 20, 449-469, 2007.

Eguchi, N. and Kodera, K.: Impact of the 2002, Southern Hemisphere, stratospheric warming on the tropical cirrus clouds and convective activity, Geophys. Res. Lett., 34, L05819, doi:10.1029/2006GL028744, 2007.

Esler, J. G., Polvani, L. M., and Scott, R. K.: The Antarctic sudden stratospheric warming of 2002: A self-tuned resonance?, Geophys. Res. Lett., 33, L12804, doi:10.1029/2006GL026034, 2006.

Fraedrich, K. and Lutz, M.: A modified time-longitude diagram applied to $500 \mathrm{mb}$ heights along $50^{\circ}$ north and south, Tellus, 39A, 25-32, 1987.
Fraedrich, K., Bantzer, C., and Burckhard, U.: Winter climate anomalies in Europe and their associated circulation at $500 \mathrm{hPa}$, Clim. Dynam., 8, 161-175, 1993.

Gabriel, A. and Schmitz, G.: The Influence of Large-Scale Eddy Flux Variability on the Zonal Mean Ozone Distribution, J. Climate, 16, 2615-2627, 2003.

Graf, H., Kirchner, I., and Perlwitz, J.: Changing lower stratospheric circulation: The role of ozone and greenhouse gases, J. Geophys. Res., 103, 11251-11261, 1998.

Harada, Y., Goto, A., Hasegawa, H., Fujikawa, N., Naoe, H., and Hirooka, T.: A major stratospheric sudden warming event in January 2009, J. Atmos. Sci., 67(6), 2052-2069, doi:10.1175/2009JAS3320.1, 2010.

Holton, J. R. and Mass, C.: Stratospheric vacillation cycles, J. Atmos. Sci., 33, 2218-2225, 1976.

Hoskins, B. and Karoly, D.: The steady response of a spherical atmosphere to thermal and orographic forcing, J. Atmos.Sci., 38, 1179-1196, 1981.

Labitzke, K. and Kunze, M.: On the remarkable Arctic winter 2008/2009, J. Geophys. Res., 114, D00I02, doi:10.1029/2009JD012273, 2009.

Labizke, K. and Naujokat, B.: The lower Arctic stratosphere in winter since 1953, SPARC News letters, http://www.atmosp.physics. utoronto.ca/SPARC/News15/15_Labitzke.html, http://www.geo. fu-berlin.de/en/met/ag/strat/produkte/northpole/index.html, 15, 11-14, 2000.

Li, T. and Fu, B.: Tropical cyclogenesis associated with Rossby wave energy dispersion of a pre-existing typhoon. Part I: Satellite data analyses, J. Atmos. Sci., 63, 1377-1389, 2006.

Limpasuvan, V., Thompson, D., and Hartmann, D.: The life cycle of the northern hemisphere sudden stratospheric warmings, J. Climate, 17, 2584-2596, 2004.

Manney, G. L., Schwartz, M. J., Krüger, K., Santee, M. L., Pawson, St., Lee, J. N., Daffer, W. H., Fuller, R. A., and Liversey, N. J.: Aura Microwave Limb Sounder observation of dynamics and transport during record-breaking 2009 Arctic stratospheric major warming, Geophys. Res. Lett., 36, L12815, doi:10.1029/2009GL038586, 2009.

Matsuno, T.: A dynamical model of stratospheric sudden warming, J. Atmos. Sci., 28, 1479-1494, 1971.

McCormick, M. P., Zawodny, J. M., Chu, W. P., Baer, J. W., Guy, J., and Ray, A.: Stratospheric aerosol and gas experiment III (SAGE III), in: Sensor Systems for the Early Earth Observing System Platforms, edited by: Barnes, W. L., Proc. Soc. Photo-Opt. Instrum. Eng., 1939, 137-149, 1993.

McIntyre, M. E.: How well do we understand the dynamics of stratospheric warmings?, J. Meteorol. Soc. Jpn., 60, 37-65, 1982.

McPhaden, M.: Evolution of the 2002/03 El Nino, BAMS, 667695, 2004.

Mukougawa, H., Hirooka, T., and Kuroda, Y.: Influence of stratospheric circulation on the predictability of the tropospheric Northern annular mode, Geophys. Res. Lett., 36, L008814, doi:10.1029/2008GRL03717, 2009.

Newman, P., Nash, E., and Rosenfield, J.: What controls the temperature of the Arctic stratosphere during the spring?, J. Geophys. Res., 106(D17), 19999-20010, 2001.

Nishii, K. and Nakamura, H.: Tropospheric influence on Antarctic ozone hole split 2002, Geophys. Res. Lett., 31, L16103, doi:10.1029/2004GL019532, 2004. 
Peters, D.: Zur resonanten Wechselwirkung von planetaren Wellen in einem Zweischichtenmodell unter Berücksichtigung der externen Anregung einer Welle. Teil 1: der Amplitudenverlauf, Z. Meteorol., 35, 239-251, 1985.

Peters, D., Vargin, P., and Körnich, H.: A Study of the Zonally Asymmetric Tropospheric Forcing of the Austral Vortex Splitting During September 2002, Tellus, 59A, 384-394, 2007.

Plumb, R. A.: Instability of the distorted polar night vortex: A theory of stratospheric warmings, J. Atmos. Sci., 38, 2514-2531, 1981.

Plumb, R. A.: On the Three-Dimensional Propagation of Stationary Waves, J. Atmos. Sci., 42, 217-229, 1985.

Randel, W. J.: Further modification of time-longitude lagcorrelation diagrams: application to three-dimensional wave propagation, Tellus, 40A, 257-271, 1988.

Randel, W. J. and Boville, B. A.: Observations of Stratospheric warming during December 1984, J. Atmos. Sci., 44(15), 21792186, 1987.

Randel, W. J. and Cobb, J. B.: Coherent variations of monthly mean total ozone and lower stratospheric temperature, J. Geophys. Res., 99, 5433-5447, 1994.

Randel, W. J. and Wu, F.: Cooling of the Arctic and Antarctic Polar Stratospheres due to Ozone Depletion, J. Climate, 12, 14671479, 1999.

Sardeshmukh, P. D. and Hoskins, B. J.: The generation of global rotational flow by steady idealized tropical divergence, J. Atmos. Sci., 45, 1228-1250, 1988.
Scaife, A. A., Jackson, D. R., Swinbank, R., Butchart, N., Thornton, H. E., Keil, M., and Henderson, L.: Stratospheric Vacillations and the Major Warming over Antarctica in 2002, J. Atmos. Sci., 62, 629-639, 2005.

Scherhag, R.: Die explosionsartigen Stratosphärenerwärmungen des Spätwinters 1951/52. Berichte des Deutschen Wetterdienstes in der US-Zone 6 (Nr. 38), 51-63, 1952.

Schoeberl, M. S.: Stratospheric warmings: observations and theory, Rev. Geophys., 16(4), 521-538, 1978.

Shindell, D. T., Wong, S., and Rind, D.: Interannual variability of the Antarctic ozone hole in a GCM. Part I: The influence of tropospheric wave variability, J. Atmos. Sci., 54, 2308-2319, 1997.

Shutts, G. J.: The propagation of eddies in diffluent jetstreams: Eddy vorticity forcing of "blocking" flow field, Q. J. Roy. Meteorol. Soc., 109, 737-761, 1983.

SPARC CCMVal, SPARC CCMVal Report on the Evaluation of Chemistry-Climate Models, edited by: Eyring, V., Shepherd, T. G., and Waugh, D. W., SPARC Report No. 5, WCRPX, WMO/TD-No. X, http://www.atmosp.physics.utoronto.ca/ SPARC, Chapter 4 "Dynamics", 2010.

Tsvetkova, N., Yushkov, V., Lukyanov, A., Dorohov, V., and Nakane, X.: Record chemical ozone loss in Arctic during winter 2004/2005, Izvestia RAN, Physics of Atmosphere and Ocean, 43(5), 643-650, 2007.

World Meteorological Organisation (WMO): Scientific Assessment of Ozone Depletion: 2006, Global Ozone Research and Moni toring Project, Report No. 50, 2006. 